\title{
Regional disease characteristics and comorbidities of patients with schizophrenia in the Ziprasidone Observational Study of Cardiac Outcomes (ZODIAC): Findings from an international large simple trial*
}

\author{
John M. Kane ${ }^{1 \#}$, Wolfgang Fleischhacker ${ }^{2}$, Francesca Kolitsopoulos ${ }^{3}$, Onur N. Karayal ${ }^{3}$, Jamie Geier $^{3}$, \\ Cynthia Siu ${ }^{4}$, Robert Reynolds ${ }^{3}$, Gerald Faich ${ }^{5}$, Brian L. Strom ${ }^{6}$ \\ ${ }^{1}$ Department of Psychiatry, Zucker Hillside Hospital, Glen Oaks, USA \\ ${ }^{2}$ Department of Biological Psychiatry, Medical University Innsbruck, Innsbruck, Austria \\ ${ }^{3}$ Pfizer Inc., New York, USA \\ ${ }^{4}$ Data Power (DP), Inc., Ringoes, USA \\ ${ }^{5}$ Department of Epidemiology, United BioSource Corporation, Blue Bell, USA \\ ${ }^{6}$ Department of Biostatistics and Epidemiology, Center for Clinical Epidemiology and Biostatistics, Center for Pharmacoepidemiol- \\ ogy Research and Training, University of Pennsylvania School of Medicine, Philadelphia, USA \\ Email: ${ }^{\#}$ JKane2@NSHS.edu
}

Received 28 September 2012; revised 29 October 2012; accepted 8 November 2012

\begin{abstract}
Background: Using baseline data from the Ziprasidone Observational Study of Cardiac Outcomes (ZODIAC), we assessed disease characteristics and prevalence of select comorbidities among subjects with schizophrenia in different clinical settings across 18 countries. ZODIAC was a randomized, open-label, one-year, large simple trial (LST) that enrolled 18,239 individuals with schizophrenia. Methods: Subjects were randomized to open-label treatment with ziprasidone $(n=9120)$ or olanzapine $(n=9119)$ in naturalistic (usual care) settings and followed for one year. Study sites $(n=749)$ applied minimal selection criteria in an attempt to make the study population as representative as possible of those receiving treatment in "real world" circumstances across the countries. Results: Mean patient age was 41 years, $55 \%$ were male, $34 \%$ were markedly ill or presented with more severe disease, and $66 \%$ of subjects had one or more select comorbid conditions [i.e. heart attack, stroke, hypertension, CAD/angina, high cholesterol/triglycerides, diabetes, or overweight (BMI $\geq 25)$ ] at baseline. History of suicide attempt was greatest in

\footnotetext{
*This study was supported by funding from Pfizer, Inc., New York, New York. These results have previously been presented in poster format at the NCDEU 2010 50th Anniversary Meeting, June 14-17, 2010; Boca Raton Hotel, Boca Raton, FL. Cynthia Siu, Ph.D. at Data Power (DP), Inc. was a paid consultant for Pfizer, Inc. in connection with the development of this manuscript. She provided editorial assistance and analysis. We thank Mr. Vito Calamia at Pfizer Inc. for programming support and data quality review in this study.

${ }^{\#}$ Corresponding author.
}

the US (38\%), compared with Sweden (34\%), Brazil/South America (26\%), Asia (23\%), and Eastern Europe (20\%). Overweight or obesity was the most prevalent comorbid risk factor, representing $60 \%$ of enrolled subjects, $70 \%$ of US subjects compared with $30 \%$ in Asia and $52 \%-64 \%$ in the other regions studied. High cholesterol/triglycerides levels were found in $23 \%$ of US subjects compared with a relatively low prevalence in other countries $(3 \%-11 \%)$. History of cardiovascular or diabetes-related comorbidities was found in $31 \%$ of subjects. Current smoking $(46.5 \%)$ and past smoking $(11.8 \%)$ were common with men dominating the proportion of current smokers: US (61\%); Asia (60\%); Sweden (50\%); Eastern Europe (49\%); and Latin America (44\%). Conclusions: Our findings indicate substantial baseline variations across countries in demographics, comorbid conditions, and psychiatric disease history. These data provide an international epidemiologic picture of schizophrenia and may help guide future research and treatment initiatives.

Keywords: Large Simple Trial; Schizophrenia; ZODIAC; Comorbidities

\section{INTRODUCTION}

Large simple trials (LSTs), with minimal selection requirements, are designed to assess the reliability, generalizability, and overall relevance of treatments in real world environments. As such, they verify and supplement findings from classical randomized controlled trials 
(RCTs) by providing robust, real-life safety and effectiveness based on observed patterns in naturalistic settings [1-3]. This is especially relevant for persons with psychotic disorders when baseline ethnic, health, and other risk factors are known to be potential moderators or mediators of psychiatric treatment outcomes $[1,4]$.

The majority of clinical and observational data on schizophrenia published to date are derived from North American and West European populations. However, these data do not capture the full scope of disability given the high percentage of persons with psychiatric disorders residing in middle- or low-income countries [5]. This has prompted criticisms [6,7] and calls to address this imbalance [8,9].

The Ziprasidone Observational Study of Cardiac Outcomes (ZODIAC) was a global, randomized, LST in schizophrenia that enrolled 18,239 subjects from 18 countries in North America, South America, Europe, and Asia [10]. It provided real-world data on outcomes for persons with schizophrenia from practice settings in diverse healthcare systems and cultures $[10,11]$.

The aim of this paper is to highlight key demographic characteristics and assess the prevalence of psychiatric comorbidities among this large cohort. Data from international studies like ZODIAC offer the advantage of comparisons that could add important insight on diversities and challenges in treating this debilitating illness.

\section{METHODS}

\subsection{Study Design}

A total of 18,239 persons diagnosed with schizophrenia, schizophreniform, and schizoaffective disorder were enrolled in the ZODIAC LST between February 2002 and February 2006 (last patient last visit: April 2007). As described in detail elsewhere [11], participants were randomized to ziprasidone or olanzapine, after which no further protocol-mandated interventions were made. The primary study goal was to determine whether there was a statistical difference between ziprasidone and olanzapine for non-suicide mortality in typical clinical situations. Inclusion criteria were broad and exclusion criteria were minimal. While initial assignment of drug was done in a random fashion, neither the physician nor the subject was blinded to treatment allocation, consistent with routine medical care. Physicians and subjects were free to change regimens and dosing based on subjects' response to the assigned medication, and use of concomitant medications, including other antipsychotics, was permitted. Patients were followed for up to 1 year, regardless of duration on randomized treatment, to evaluate study outcomes. No laboratory testing or clinical monitoring was required by the protocol; rather, visits and tests were performed at the discretion of the treating physician.

\subsection{Study Assessments}

Baseline questionnaires were completed by the treating clinicians or other study team members. Data on patient characteristics included age, height, weight, race (e.g. Caucasian/white, African-American/black, Asian/Pacific islander, Hispanic/Latino, other), smoking status (e.g. current smoker, past smoker, never smoked, unknown), age of onset and severity of schizophrenia (assessed using the Clinical Impression Scale [CIS], which is equivalent to the Clinical Global Impression [CGI] scale), number of previous psychiatric hospitalizations, history of suicide attempts, prior antipsychotic use (including ziprasidone or olanzapine), family and personal history of cardiovascular disease (CVD) and metabolic risks (e.g. heart attack, stroke, hypertension, coronary artery disease/angina, arrhythmia, high cholesterol/triglycerides), history of diabetes diagnoses and prior use of insulin or oral hypoglycemics, and other concomitant medication use and smoking status as reported by subject or caregiver.

The study follow-up form included questions on antipsychotic medication use, incidence of diabetes since last study visit, current diabetic therapy, height, weight, emergency room visit or hospitalization, and patient vital status since the last visit.

\subsection{Statistical Methods}

Pearson chi-square for categorical variables and F-test for continuous variables were used to compare patient characteristics and prevalence rates of comorbidities among subjects in different regions. Multivariate logistic regression models and ANCOVA were applied to evaluate cross-sectional associations of patient characteristics with comorbidities and polypharmacy (number of antipsychotic medications currently used $>1$ ). Patient characteristics collected included age, gender, race, duration of illness, smoking status, CIS score, psychiatric inpatient hospitalization experience, and history of suicide attempts. Duration of illness was derived as the time from date of diagnosis (self-reported) to the randomization date, or as "age-age of onset +1 ". All reported p-values were 2-sided, and $\mathrm{p}<0.05$ was considered statistically significant. Multiplicity adjustment was not performed in this post-hoc, exploratory analysis. All analyses were performed with SAS/STAT, version 4.3 of the SAS system.

\section{Results}

\subsection{Patient Characteristics}

Subject demographics and baseline prevalence of comorbid conditions are presented in Table 1. Mean age was 41 years (range 18 -96) and $55 \%$ of subjects were 


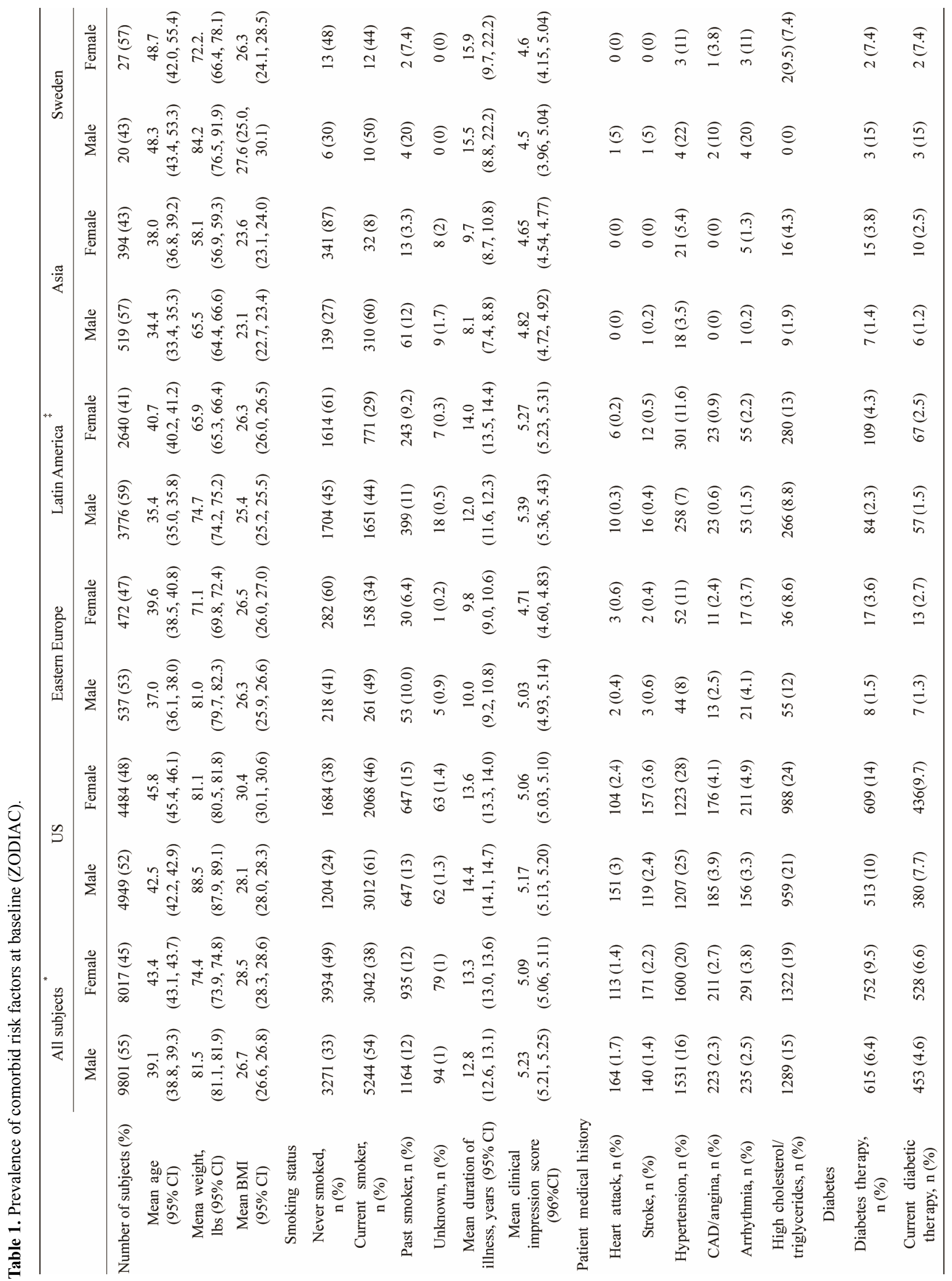




\begin{tabular}{|c|c|c|c|c|c|c|c|c|c|c|c|c|c|}
\hline 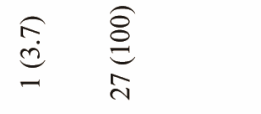 & $\stackrel{\varrho}{0}$ & $\begin{array}{l}\widehat{\sigma} \\
\stackrel{6}{6} \\
-\end{array}$ & త్ర్ర & $\underbrace{\widehat{\Xi}}_{\text {in }}$ & $\underset{\widetilde{d}}{\overparen{d}}$ & $\begin{array}{c}\infty \\
\stackrel{0}{n} \\
n \\
n\end{array}$ & & 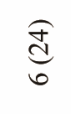 & $\widehat{\vec{d}}$ & $\widehat{\widehat{\vartheta}}$ & $\underset{\mathrm{d}}{\mathbb{d}}$ & $\underset{\sim}{\widehat{N}}$ & 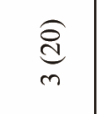 \\
\hline$\underset{\infty}{\stackrel{\infty}{\infty}}$ & $\underset{\sim}{\stackrel{\varrho}{巳}}$ & $\underset{\infty}{\stackrel{9}{+}}$ & $\underset{\sim}{\stackrel{\vartheta}{(}}$ & $\underset{\infty}{\stackrel{9}{+}}$ & $\underset{\sigma}{\frac{1}{8}}$ & $\underset{\mathfrak{\Xi}}{\stackrel{\Xi}{\Xi}}$ & & $\underset{\infty}{\stackrel{f}{f}}$ & $\underset{m}{\stackrel{\infty}{\rightleftarrows}}$ & 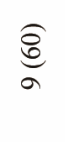 & $\underset{\sim}{\stackrel{\Xi}{(}}$ & $\widehat{\sigma}$ & $\underset{\mathrm{q}}{\stackrel{\vartheta}{+}}$ \\
\hline 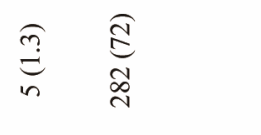 & 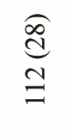 & $\begin{array}{l}\frac{n}{6} \\
\frac{\infty}{2}\end{array}$ & 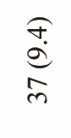 & 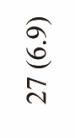 & $\frac{\widehat{d}}{2}$ & $\begin{array}{l}\widehat{\nwarrow ্} \\
\bar{\beth}\end{array}$ & & 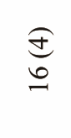 & 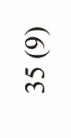 & $\begin{array}{l}\widehat{\stackrel{d}{d}} \\
\stackrel{o}{G}\end{array}$ & 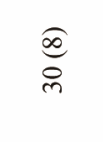 & $\widehat{d}$ & 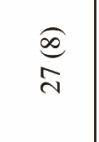 \\
\hline 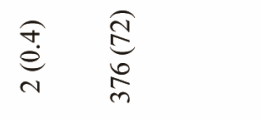 & 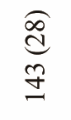 & 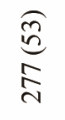 & 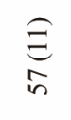 & 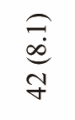 & $\underset{\mathbb{d}}{\stackrel{\mathbb{d}}{\Xi}}$ & 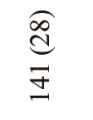 & & $\underset{n}{n}$ & $\frac{e}{m}$ & 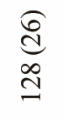 & $\underset{m}{E}$ & $\underset{\mathrm{N}}{\stackrel{f}{E}}$ & 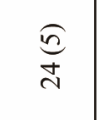 \\
\hline 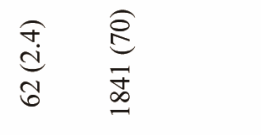 & $\begin{array}{l}\stackrel{0}{0} \\
\stackrel{0}{\infty} \\
\stackrel{\sigma}{i}\end{array}$ & $\begin{array}{l}\widehat{\vec{n}} \\
\stackrel{m}{m}\end{array}$ & $\begin{array}{l}\hat{\sigma} \\
\stackrel{s}{s} \\
\hat{i}\end{array}$ & 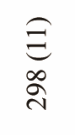 & 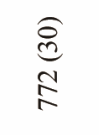 & $\begin{array}{l}\text { 点 } \\
\text { 㠻 }\end{array}$ & & $\frac{\widehat{d}}{\widehat{\widehat{\sigma}}}$ & 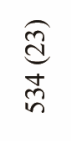 & $\begin{array}{l}\widehat{\sigma} \\
\stackrel{g}{ \pm}\end{array}$ & $\begin{array}{l}\underset{d}{d} \\
\substack{\infty \\
n \\
n}\end{array}$ & $\stackrel{\frac{n}{\sigma}}{\frac{0}{m}}$ & 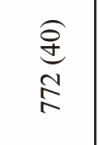 \\
\hline 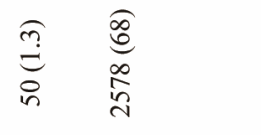 & $\begin{array}{l}\widehat{\widehat{c}} \\
\infty \\
\stackrel{\Xi}{\Xi}\end{array}$ & 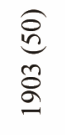 & 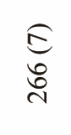 & $\widehat{\Xi}$ & $\underset{\substack{\tilde{d} \\
\infty}}{\widehat{\infty}}$ & 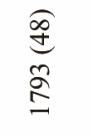 & & 矛 & $\begin{array}{l}\text { d् } \\
\text { o }\end{array}$ & 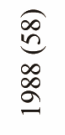 & $\begin{array}{l}\text { త্రి } \\
\stackrel{2}{2}\end{array}$ & 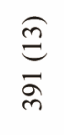 & $\begin{array}{l}0 \\
0 \\
0 \\
o \\
o \\
0\end{array}$ \\
\hline$\frac{\widehat{a}}{\bar{q}}$ & $\underset{F}{\stackrel{\sigma}{\infty}}$ & $\begin{array}{l}\widehat{\hat{\theta}} \\
\infty \\
\stackrel{\text { ते }}{0}\end{array}$ & $\stackrel{5}{5}$ & 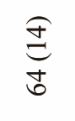 & $\underset{\infty}{\stackrel{\sigma}{\sigma}}$ & 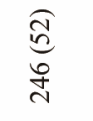 & & $\underset{\mathbb{N}}{\stackrel{6}{a}}$ & 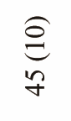 & 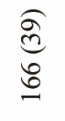 & $\begin{array}{l}\underset{d}{d} \\
\text { J }\end{array}$ & 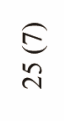 & $\underset{\substack{\infty \\
i n}}{\stackrel{\infty}{=}}$ \\
\hline 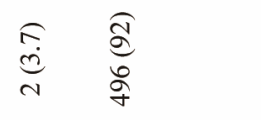 & $\begin{array}{l}\underset{6}{0} \\
\ddots \\
F\end{array}$ & 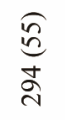 & $\underset{\sigma}{E}$ & $\begin{array}{l}\text { @્d } \\
0\end{array}$ & $\begin{array}{l}\underset{\mathrm{d}}{\widetilde{\Xi}} \\
\stackrel{0}{ }\end{array}$ & $\begin{array}{l}\widehat{\infty} \\
\stackrel{0}{0} \\
\hat{0} \\
0\end{array}$ & & $\underbrace{n}_{b}$ & $\underset{\mathfrak{g}}{\stackrel{O}{g}}$ & 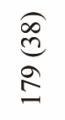 & $\underset{\mathrm{d}}{\widehat{d}}$ & $\underset{m}{\infty}$ & $\underset{\mathscr{0}}{\stackrel{\sigma}{0}}$ \\
\hline 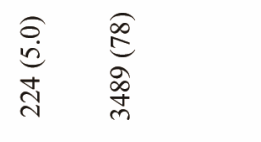 & $\begin{array}{l}\underset{\mathcal{d}}{\cong ్} \\
\stackrel{\alpha}{\alpha}\end{array}$ & \begin{tabular}{l}
$\widehat{\sigma}$ \\
\multirow{్}{\hat{~}}{} \\
\end{tabular} & $\begin{array}{l}\underset{\Xi}{\Xi} \\
o ̛ d \\
\stackrel{d}{n}\end{array}$ & 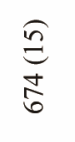 & $\begin{array}{l}\underset{\mathcal{J}}{\stackrel{J}{\infty}} \\
\stackrel{\infty}{\Xi}\end{array}$ & $\begin{array}{l}\widehat{\mathbb{S}} \\
\infty \\
\infty \\
\infty\end{array}$ & & $\begin{array}{l}\underset{ \pm}{\stackrel{f}{E}} \\
\stackrel{\Xi}{=}\end{array}$ & 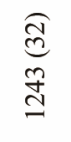 & $\begin{array}{l}\text { ô } \\
\text { o } \\
\text { id }\end{array}$ & $\begin{array}{l}\stackrel{E}{n} \\
\stackrel{m}{\cong}\end{array}$ & $\begin{array}{l}\underset{0}{0} \\
\text { in }\end{array}$ & 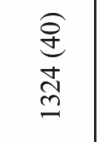 \\
\hline $\begin{array}{l}\widehat{O} \\
\vec{\delta} \\
\overline{0}\end{array}$ & $\begin{array}{l}\widehat{a} \\
\vec{d} \\
\stackrel{\vec{d}}{a}\end{array}$ & 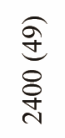 & $\underset{\substack{\hat{D} \\
i n}}{\widehat{G}}$ & $\underset{\substack{a \\
a}}{\stackrel{\infty}{=}}$ & $\begin{array}{l}\widehat{\hat{n}} \\
\hat{n}\end{array}$ & 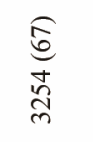 & & $\begin{array}{l}\stackrel{\infty}{\infty} \\
\stackrel{n}{n} \\
\hat{n}\end{array}$ & 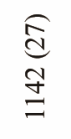 & $\begin{array}{l}\widehat{\hat{n}} \\
\frac{0}{2} \\
\frac{2}{2}\end{array}$ & $\begin{array}{l}\widehat{\widetilde{c}} \\
\stackrel{0}{\mathbb{I}}\end{array}$ & 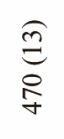 & $\begin{array}{l}\widehat{\hat{n}} \\
\stackrel{\infty}{=}\end{array}$ \\
\hline 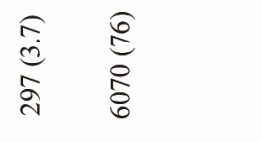 & 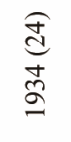 & $\begin{array}{l}\widehat{\widehat{d}} \\
\stackrel{6}{J} \\
\vec{J}\end{array}$ & 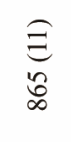 & $\begin{array}{l}\widehat{\Re} \\
\stackrel{\infty}{0} \\
\stackrel{0}{0}\end{array}$ & 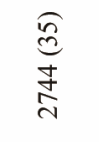 & $\begin{array}{l}\widehat{\hat{\theta}} \\
\overline{\bar{n}} \\
\text { in }\end{array}$ & & 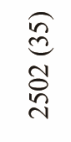 & 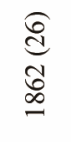 & $\begin{array}{l}\widehat{\infty} \\
\stackrel{\infty}{n} \\
\cdots \\
\hat{q} \\
\dot{q}\end{array}$ & 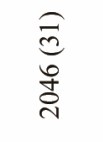 & 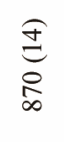 & $\begin{array}{l}\hat{\sigma} \\
\underset{0}{ \pm} \\
\frac{\infty}{N}\end{array}$ \\
\hline $\begin{array}{l}\sqrt{2} \\
8 \\
0 \\
0\end{array}$ & 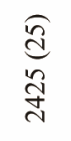 & 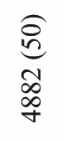 & $\begin{array}{l}\underset{Ð}{\varrho} \\
\stackrel{0}{O}\end{array}$ & $\underset{\stackrel{\Xi}{\Xi}}{\stackrel{\Xi}{\Xi}}$ & \begin{tabular}{l}
$\widehat{\infty}$ \\
$\stackrel{d}{d}$ \\
\multirow{d}{*}{} \\
d
\end{tabular} & $\begin{array}{l}\text { in } \\
\text { o } \\
\text { in } \\
\text { n }\end{array}$ & & 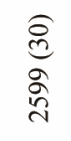 & $\begin{array}{l}\widehat{d} \\
\frac{n}{a} \\
\frac{a}{a}\end{array}$ & \begin{tabular}{l}
$\widehat{\hat{n}}$ \\
\multirow{0}{*}{} \\
亲
\end{tabular} & 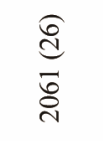 & $\underset{\infty}{\widehat{\Xi}}$ & 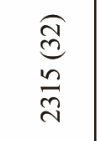 \\
\hline 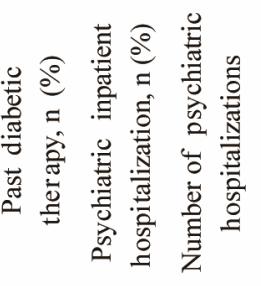 & 0 & $\stackrel{n}{1}$ & $\hat{b}$ & $\stackrel{t}{\sigma}$ & 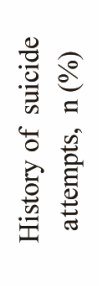 & 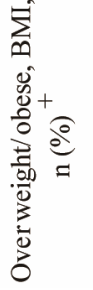 & 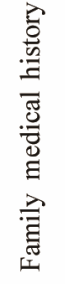 & 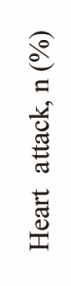 & 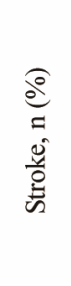 & 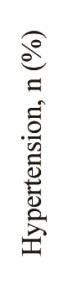 & 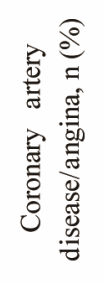 & 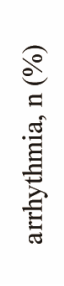 & 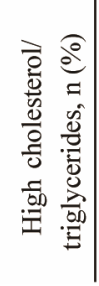 \\
\hline
\end{tabular}


male. US subjects were older (mean age: 43 years), compared with other regions (mean ages $34-40$ years). Age (age deciles $<20,20$ - 29 through 60 - 69, $\geq 70$ ), and gender distributions varied significantly across regions $(\mathrm{p}<$ 0.001 for age by region; $\mathrm{p}<0.001$ for gender by region; $\mathrm{p}<0.001$ for age by gender by region).

Enrolled subjects were diagnosed with schizophrenia on average for 13 years; only $10 \%$ (1814 of 17,904 subjects) had duration of illness less than 6 months (from the date of diagnosis). Average duration of illness was long in the US (14.0 years, 95\% CI: 13.8 to 14.3 years) and the shortest was in Asia (8.8 years, 95\% CI: 8.2 to 9.4 years).

Current smoking (46.5\%) and past smoking (11.8\%) were common among this study population (Table 1) with men dominating the proportion of current smokers: US (61\%); Asia (60\%); Eastern Europe (49\%); and Latin America (44\%) ( $\mathrm{p}<0.001$, smoking status by region; $\mathrm{p}<$ 0.001 smoking status by gender; smoking status by gender by region, $\mathrm{p}<0.001)$.

Mental illness severity as assessed by CIS score differed among regions after adjusting for age, gender, and race ( $p<0.001$, ANCOVA). The percentages of markedly ill or more severe subjects varied by country as follows: Brazil (45\%), the US (32\%), Asia (24\%), and the other regions studied $(31 \%-35 \%)$. History of psychiatric inpatient hospitalization was highest in Eastern Europe (92\%), compared with the US (78\%) and the other regions studied $(69 \%-72 \%)$. The majority of subjects took one antipsychotic medication regardless of geographic region (Table 2). Subjects in the US had the highest prevalence of concomitant medication use (81\%), compared with Eastern Europe (52\%) and the other countries $(72 \%-75 \%)$.

\subsection{Comorbidities and Family Medical History}

The majority of subjects $(66 \%, 11,989 / 18,239)$ entered the study with one or more select comorbid conditions [i.e. heart attack, stroke, hypertension, $\mathrm{CAD} /$ angina, high cholesterol/triglycerides, diabetes, or overweight (BMI $\geq$ 25)] as shown in Table 1. Overweight or obesity (defined as $\mathrm{BMI} \geq 25$ ) was the most prevalent comorbid risk factor, representing $60 \%$ of enrolled subjects. ZODIAC subjects had a mean weight of $81.5 \mathrm{~kg}(95 \% \mathrm{CI}: 81.1$ to 81.9 ) for men, and $74.4 \mathrm{~kg}$ (73.9 to 74.8) for women. Overweight or obesity (BMI $\geq 25$ ) was seen in $69 \%$ of US subjects compared with $30 \%$ in Asia and other regions $(51 \%$ - 63\%) (Table 1).

History of cardiovascular or diabetes-related comorbidities was found in $31 \%$ of subjects. Simultaneous presence of multiple CVDs were present in $12 \%$ of subjects, 14\% (1143/8007) of women and 11\% (1035/9787) of men. Hypertension was the most common cardiovascular comorbidity (16\% men vs. $20 \%$ women) and prevalence was highest in the US, followed by Sweden, Eastern Europe, Latin America, and Asia. Prevalence of high cholesterol/triglycerides was also reported in $15 \%$ of subjects, ranging from $8.8 \%$ in Latin American men to $24 \%$ in US women. History of Coronary Artery Disease (CAD)/angina and arrhythmia was approximately 3.0\%, and was comparable between the US and Eastern Europe; estimates were lower in remaining regions. History of heart attack or stroke was about $3 \%$ in the US but less than $1 \%$ in other regions.

Family medical history of select comorbidities were collected with US subjects reporting a higher prevalence of a family history of heart attack (41\%), high cholesterol/triglycerides (37\%), CAD/angina (34\%), stroke $(30 \%)$, and arrhythmia (15\%) compared with other regions (Table 1).

\subsection{Correlations between Comorbid Conditions, and Polypharmacy}

Table 3 shows selected comorbidities by duration of illness ( $<5$ years vs. $\geq 5$ years). The likelihood of having at least one of these comorbid factors increased with duration of illness (or age) $(\mathrm{t}=4.14, \mathrm{p}<0.001)$, number of antipsychotic medications currently used $(\mathrm{t}=4.12, \mathrm{p}<$ $0.001)$, and smoking $(\mathrm{t}=6.36, \mathrm{p}<0.001)$, independent of gender, race, regions, and severity of illness (multivariate logistic regression analysis). There was a positive association between the duration of mental illness and likelihood of being overweight/obese $(t=2.64, p<0.008)$, after adjusting for region, race, gender, severity of mental illness, and other cardiovascular/diabetes comorbidities.

Table 2. Antipsychotic Medication Use History.

\begin{tabular}{|c|c|c|c|c|c|}
\hline & All subjects & US & Eastern Europe & Latin America & Asia \\
\hline Number of subjects & 18,229 & 9735 & 1022 & 6504 & 921 \\
\hline Current antipsychotic medication use, n (\%) & $14,404(79 \%)$ & $7207(74 \%)$ & $797(78 \%)$ & $5543(85 \%)$ & $823(89 \%)$ \\
\hline \multicolumn{6}{|l|}{ Number of antipsychotic medications currently used } \\
\hline None & $3825(21 \%)$ & $2528(26 \%)$ & $225(22 \%)$ & $961(15 \%)$ & $98(11 \%)$ \\
\hline 1 & $10,679(59 \%)$ & $5724(59 \%)$ & $638(62 \%)$ & $3770(58 \%)$ & $519(56 \%)$ \\
\hline$\geq 2$ & $3725(20 \%)$ & $1483(15 \%)$ & $159(16 \%)$ & $1773(27 \%)$ & $304(33 \%)$ \\
\hline
\end{tabular}


Table 3. Comorbidities in ZODIAC by illness duration.

\begin{tabular}{|c|c|c|c|}
\hline & \multicolumn{2}{|c|}{ Duration } & \multirow[b]{2}{*}{ p-value } \\
\hline & $<5$ Years & $\geq 5$ Years & \\
\hline Number of subjects & 5897 & 12,016 & \\
\hline \multicolumn{4}{|l|}{ Number of comorbid factors ${ }^{\dagger}$} \\
\hline 1 Comorbid factor & $2316(40 \%)$ & $4869(41 \%)$ & $<0.001$ \\
\hline 2 Comorbid factors & $687(12 \%)$ & $2037(17 \%)$ & \\
\hline$\geq \mathbf{3}$ Comorbid factors & $269(5.4 \%)$ & $909(9.1 \%)$ & \\
\hline None & $2378(41 \%)$ & $3515(30 \%)$ & \\
\hline Psychiatric inpatient hospitalizations & $3430(58 \%)$ & $10,065(84 \%)$ & $<0.001$ \\
\hline History of suicide attempts & $1660(29 \%)$ & $3724(32 \%)$ & $<0.001$ \\
\hline \multicolumn{4}{|c|}{ Number of antipsychotic medications currently used } \\
\hline None & $1702(29 \%)$ & $2017(17 \%)$ & $<0.001$ \\
\hline 1 & $3339(57 \%)$ & $7191(60 \%)$ & \\
\hline$\geq 2$ & $851(14 \%)$ & $2803(23 \%)$ & \\
\hline \multicolumn{4}{|l|}{ Smoking status } \\
\hline Never smoked & $2723(46 \%)$ & $4524(38 \%)$ & $<0.001$ \\
\hline
\end{tabular}

\footnotetext{
${ }^{\dagger}$ Comorbid factors: cardiovascular (heart attack, stroke, hypertension, CAD/angina, high cholesterol/triglycerides), diabetes, or overweight (BMI $\geq 25$ ).
}

Polypharmacy was more frequent in men (23\%) than in women $(18 \%)(\mathrm{t}=6.50, \mathrm{p}<0.001)$, in overweight subjects $(t=6.13, p<0.001)$, persons with more severe mental illness as assessed by CIS score $(t=18.20, p<$ $0.001)$, and longer duration of illness (or age) $(\mathrm{t}=14.05$, $\mathrm{p}<0.001$ ). No association was found between antipsychotic polypharmacy and the prevalence of other cardiovascular or diabetes comorbidities $(t=0.84, p=0.401)$ after adjusting for race and regions (logistic regression analysis).

\subsection{Early Phase Patient Subgroup Analysis}

Only 1814 subjects reported duration of illness less than 6 months. Among this subgroup, the prevalence of comorbid conditions was: $51 \%$ for overweight/obesity, $22 \%$ for obesity, $23 \%$ for one or more cardiovascular morbidities, and $8.1 \%$ for the presence of multiple $(\geq 2)$ cardiovascular comorbidities. Estimates were all significantly lower than those observed in subjects with 6 months or longer duration of illness (all $p<0.001$ ), independent of region and gender.

\section{DISCUSSION}

ZODIAC is the largest prospective, randomized study of subjects with schizophrenia conducted to date [10]. Since procedures and data collection were greatly simplified compared with RCTs, this study elucidates the demographic profile of persons with schizophrenia in naturalistic clinical settings. There are, however, similarities/ differences in patient demographics and characteristics across regions and countries.

There are few, but notable examples of cross-national observational studies of comparable scale including the W-SOHO (Worldwide-Schizophrenia Outpatient Health Outcome) study, which pooled data from the SOHO (Schizophrenia Outpatient Health Outcome) observational study in 10 Western European countries and the IC-SOHO (Inter-Continental SOHO) study in 27 other countries $[1,12,13]$; the METEOR study in 16 European countries [14]; and the randomized SCoP safety trial on schizophrenia subjects across Europe and Asia [15]. However, due to the paucity of published data summarizing cross-national information on comorbidities and risk factors prevalent in schizophrenia subjects, we highlight key country and region-specific comparisons from other schizophrenia trial populations whenever available.

In ZODIAC, most subjects were diagnosed with schizophrenia for over ten years and $10 \%$ were diagnosed within 6 months of study enrollment. Longer dura- 
tion of illness appeared to be associated with poorer clinical outcomes evidenced by more reported comorbidities, e.g. heart attack, stroke, and heavy antipsychotic medication use (i.e. more reliance on polypharmacy) in those with five or more years of illness compared with less than five years (Table 3). A subgroup analysis of subjects with duration of illness less than 6 months also confirmed these findings.

History of psychiatric inpatient hospitalization was higher (92\%) in Eastern Europe, compared with the US $(79 \%)$ and the other regions studied $(69 \%-72 \%)$. This finding is consistent with use of long-term institutionalization as an acceptable local practice in psychiatric treatment and management in this region [16-20].

It is known that persons with schizophrenia also have a high burden of comorbidities that may be manifestations of the illness itself, poor diet and lifestyle, poor access to healthcare, or the propensity to develop CVD and other health problems [21-23]. As a result, mortality rates are two to three times higher among persons with schizophrenia than that of the general population [24-27] and corresponding elevated risks of dying from a wide range of somatic conditions and risk factors three to ten times higher [26]. Excess CVD mortality may be attributed to prevalence of risk factors commonly referred to as metabolic syndrome $[28,29]$, a problem that is compounded by increased use of second-generation antipsychotics, as several agents are associated with excess, undesirable weight, and metabolic side-effects [30-33].

Metabolic and related risks, e.g. hypertriglyceridemia, overweight/obesity, were common among ZODIAC subjects. Sixty percent of subjects were considered overweight or obese (with a BMI $\geq 25$ ) compared with $29.4 \%$ of European subjects with schizophrenia (obesity $=\mathrm{BMI}$ $>30$ ) in the METEOR study [14], 32.8\% in a physician-based survey in Europe [34], 76\% of Brazilian subjects (overweight or obese $=$ BMI $>25$ ) [35], and 33.3 to $39.8 \%$ in Taiwanese subjects (obese $=$ BMI $\geq 26.4$ or 27 ) [36,37]. Overall, Asian subjects reported better cardiovascular and metabolic profiles compared with the other cohorts, possibly owing to Asian culture, lifestyle, and diet $[38,39]$. Rates of hypertension and diabetes in ZODIAC, at $16 \%$ and $6.4 \%$ respectively, are corroborated by other trials in this patient population [34,37,40-41]. Metabolic and associated risks were highly prevalent among ZODIAC subjects, underscoring the severe public health challenge they pose to this at-risk population.

Although anti-smoking campaigns have made health risks associated with tobacco use clear to the general public, high rates of smoking are reported among individuals with schizophrenia [42,43] compared with the worldwide current smoker prevalence rate of $26 \%$ [27]. Evidence suggests that some persons with schizophrenia might smoke as a form of self-medication, to ameliorate the positive and negative symptoms, cognitive (memory/attention) deficits, mood changes and stress associated with the disease, or the side-effects produced by antipsychotic medications [44-48]. Regardless, the prevalence of smoking among persons with schizophrenia is two to three times higher than in the general population and approximately $50 \%$ higher than similar, elevated rates of smoking in people with other psychiatric diagnoses [49-54]. ZODIAC rates were consistent with these findings $(>40 \%$ of subjects were reportedly current smokers) with prevalence highest among US (61\%) and Asian (60\%) men. Male smokers outnumbered female smokers in each region perhaps due, in part, to cultural norms regarding smoking behaviors [55-57]. Further, patients with schizophrenia who smoke have a multi-fold increase in risk of dying from CVD even when compared to those who are nonsmokers [58], and also shown in ZODIAC, heavy addiction to cigarettes is clearly an important factor contributing to elevated mortality and morbidities in schizophrenia [44,59-60].

Given the high prevalence of health risks and family history of CVD observed in ZODIAC, personal history was expected to corroborate these data. Instead, investigators reported relatively low prevalence in personal history of heart attack, diabetes, and other cardiovascular ailments across all regions. This, however, might reflect the common phenomenon of under diagnosis of these comorbidities among psychiatric subjects. The awareness of, and hence diagnosis and monitoring of these comorbidities have been low among mental healthcare providers [61], and psychiatrists were the source of these data in this study. Despite repeated calls for attention, the under diagnosis and under monitoring of medical comorbidities, either as baseline conditions or as treatment emergent side-effects, persist among mental health professionals [62,63]. A related but more ominous possibility is the possibility of a "weeding-out" process; given the elevated risks from comorbidities mentioned above, under treatment and diagnosis, few schizophrenia patients survived to leave a history $[64,65]$.

This study also has some inherent limitations that deserve attention. Despite its large-scale and global design, ZODIAC findings may be skewed by its imbalanced country and regional samples. Of course, it is prudent to always exercise caution when extrapolating from regional findings to specific countries, especially those in large, diverse regions such as Asia [66,67]. Moreover, Sweden's study sample, the only participating country from Western Europe, was too small to serve as an adequate surrogate for the entire region. In addition, systematic training was not done in order to achieve inter-rater reliability on clinically subjective measure like illness severity across countries and regions. Finally, the ZODIAC study was not designed to test regional differences 
in study outcomes. Of particular importance to this paper, the methods used to enroll patients were not the same in all countries $[10,11]$.

ZODIAC provides valuable cross-country and regional information on schizophrenia disease history and manifestations, related risks, and comorbidities, which have important implications for clinical research, patient management, and mental healthcare policy in the 18 countries studied. Further, it provides important insights on conduct and interpretation of international trials, as well as, adaptation of clinical practice and customization of guidelines for mental healthcare management to specific regions.

\section{CONTRIBUTORS}

Dr. Siu wrote the first draft of the paper. Statistical analysis was performed by Dr. Siu. Drs Reynolds, Geier, Karayal, and Mrs Kolitsopoulos are full-time employees and shareholders of Pfizer.

\section{CONFLICT OF INTEREST AND AUTHOR DISCLOSURE}

Dr. Kane served as a consultant to Pfizer in connection with the scientific oversight of the study and served as a consultant or advisory board or speakers bureau for Alkermes, Amgen, AstraZeneca, Bristol-Myers Squibb, Cephalon, Eli Lilly, Intracellular Therapeutics, Janssen, Johnson \& Johnson, Lundbeck, Merck, Novartis, Otsuka, Pierre Fabre, Proteus Biomedical, Roche, and Sunovion, and is a MedAvante shareholder. Dr. Fleischhacker receives research grants from Otsuka, Pfizer, Janssen, Alkermes, Eli Lilly; consulting honoraria from Lundbeck, Roche, BMS, Otsuka, Janssen, Pfizer, Unitedbiosource, MedAvante, Sunovion, Merck; speaker honoraria from Lundbeck, Sunovion, Janssen, Eli Lilly, Otsuka, Astra Zeneca; and owns MedAvante stocks. Dr. Strom is an employee of the University of Pennsylvania, which received financial support from Pfizer in connection with the scientific oversight of the study and the development of this manuscript. He also served as consultant to Pfizer on topics not related to this study and has consulted for Abbott Laboratories, American College of Neuropsychopharmacology, American Medical Association, Astra-Zeneca, Berlex, Biogen, Blue Cross Blue Shield, Bristol-Myers Squibb, Boehringer Ingelheim, Centocor, Cephalon, CV Therapeutics, Cygnus Corporation, Daichii, Eli Lilly, Forest, GlaxoSmithKline, Hoyle Consulting, Johnson \& Johnson, Medco, Mediwound, Novartis, NPS Pharma, NUVO Research, Ocient, Pfizer, Pharm Research, PhRMA Foundation, Sanofi-Aventis, Shire, TAP Pharmaceuticals, Teva Neuroscience, and Wyeth. Dr. Ruskin served as a consultant to Pfizer in connection with the scientific oversight of the study and has served as a consultant or scientific advisory board member for Astellas, AstraZeneca, BristolMyers Squibb, Cardiome, Epix, Forest Labs, Genzyme, Javelin, Lundbeck, Millennium, Myriad, Novartis, NovoNordisk, Portola, Purdue, Sanofi-Aventis, Sequel, Sunesis, and Theravance. Dr. Faich is an employee of United BioSource Corporation, which received financial support from Pfizer in connection with the scientific oversight of the study and the development of this manuscript. Dr. Siu is a paid consultant to Pfizer Inc. and Sunovion. Drs. Reynolds, Geier, Karayal, and
Mrs Kolitsopoulos are full-time employees and shareholder of Pfizer.

\section{REFERENCES}

[1] Karagianis, J., Novick, D., Pecenak, J., et al. (2009) Worldwide-Schizophrenia Outpatient Health Outcomes (W-SOHO): Baseline characteristics of pan-regional observational data from more than 17,000 patients. International Journal of Clinical Practice, 63, 1578-1588. doi:10.1111/j.1742-1241.2009.02191.x

[2] Peto, R., Collins, R., Gray, R. (1995) Large-scale randomized trials and overviews of trials. Journal of Clinical Epidemiology, 48, 23-40. doi:10.1016/0895-4356(94)00150-O

[3] Peto, R., Baigent, C. (1998) Trials: The next 50 years: Large scale randomized evidence of moderate benefits. British Medical Journal, 317, 1170-1171. doi:10.1136/bmj.317.7167.1170

[4] Stroup, T.S. (2011) What can large simple trials do for psychiatry? America Journal of Psychiatry, 168, 117-119. doi:10.1176/appi.ajp.2010.10111652

[5] Thornley, B., Adams, C. (1998) Content and quality of 2000 controlled trials in schizophrenia over 50 years. British Medical Journal, 317, 1181-1184. doi:10.1136/bmj.317.7167.1181

[6] Saxena, S., Paraje, G., Sharen, P., et al. (2006) The 10/90 divide in mental health research trends over a 10 -year period. The British Journal of Psychiatry, 188, 81-82. doi:10.1192/bjp.bp.105.011221

[7] Saxana, S., Thornicroft, G., Krapp, M., Whiteford, H. (2007) Resources for mental health: Scarcity, inequality and inefficiency. Lancet, 370, 878-889. doi:10.1016/S0140-6736(07)61239-2

[8] Patel, V., Prince, M. (2010) Global mental health: A new global health field comes of age. Journal of the American Medical Association, 303, 1976-1977. doi:10.1001/jama.2010.616

[9] The World Health Organization (WHO) (2010) Movement for Global Mental Health and mhGAP (the mental health Global Action Program). Http://www.globalmentalhealth.org

[10] Strom, B.L., Eng, S.M., Faich, G., et al. (2011) Comparative mortality associated with ziprasidone and olanzapine in real-world use among 18,154 subjects with schizophrenia: The Ziprasidone Observational study of Cardiac Outcome (ZODIAC). American Journal of Psychiatry, 168, 193-201. doi:10.1176/appi.ajp.2010.08040484

[11] Strom, B.L., Faich, G.A., Reynolds, R.F., et al. (2008) The Ziprasidone Observational Study of Cardiac Outcomes (ZODIAC): Designs and baseline subject characteristics. Journal of Clinical Psychiatry, 69, 114-121.

[12] Dossenbach, M., Erol, A., el Mahfoud-Kessaci, M. et al. (2004) Effectiveness of antipsychotic treatments for schizophrenia: Interim 6-month analysis from a prospective, observational study (IC-SOHO) study comparing olanzapine, quetiapine, risperidone and haloperidol. Journal of Clinical Psychiatry, 65, 312-321.

doi:10.4088/JCP.v65n0305 
[13] Haro, J.M., Edgell, E.T., Jones, P.B., et al. (2003) The European Schizophrenia Outpatient Health Outcomes (SOHO) study: Rationale, methods and recruitment. Acta Psychiatrica Scandinavica, 107, 222-232. doi:10.1034/j.1600-0447.2003.00064.x

[14] De Hert, M., et al. (2010) The METEOR study of diabetes and other metabolic disorders in patients with schizophrenia treated with antipsychotic drugs. I. Methodology. International Journal of Methods in Psychiatric Research, 19, 195-210. doi: $10.1002 / \mathrm{mpr} .322$

[15] Thomas, S.H.L., Drici, M.D., Hall, G.C., et al. (2010) Safety of sertindole versus risperidone in schizophrenia: Principal results of the sertindole cohort prospective study (SCoP). Acta Psychiatrica Scandinavica, 122. 345355. doi:10.1111/j.1600-0447.2010.01563.x

[16] Furedi, J., Mohr, P., Swingler, D., et al. (2006) Psychiatry in selected countries of Central and Eastern Europe: An overview of the current situation. Acta Psychiatrica Scandinavica, 114, 223-231. doi:10.1111/j.1600-0447.2006.00804.x

[17] Kosnar, K. (2003) Mentally ill patients in central Europe being kept in padlocked, caged beds. British Medical Journal, 327, 1249. doi:10.1136/bmj.327.7426.1249-c

[18] Polubinskaya, S.V. (2000) Reform in psychiatry in postSoviet countries. Acta Psychiatrica Scandinavica, 101, 106-108. doi:10.1111/j.0902-4441.2000.007s020[dash]24.x

[19] Rybakowski, J.K. (2004) Academic psychiatry in Poland: Adjustment to rapid changes. Molecular Psychiatry, 9, 813-815. doi:10.1038/sj.mp.4001569

[20] Tomov, T. (2001) Mental health reforms in Eastern Europe. Acta Psychiatrica Scandinavica, 104, 21-26. doi:10.1034/j.1600-0447.2001.1040s2021.x

[21] Brown, S., Birtwistle, J., Roe, L. et al. (1999) The unhealthy lifestyle of people with schizophrenia. Psychological Medicine, 29, 697-701. doi:10.1017/S0033291798008186

[22] Hennekens, C.H., Hennekens, A.R., Hollar, D., Casey, D.H. (2005) Schizophrenia and increased risks of cardiovascular disease. American Heart Journal, 150, 11151121. doi:10.1016/i.ahj.2005.02.007

[23] Strassnig, M., Brar, J.S., Ganguli, R. (2003) Nutritional assessment of patients with schizophrenia: A preliminary study. Schizophrenia Bulletin, 29, 393-397. doi:10.1093/oxfordjournals.schbul.a007013

[24] Auquier, P., Lancon, C., Rouillon, F., Lader, M. (2007) Mortality in schizophrenia. Pharmacoepidemiol Drug Safety, 16, 1308-1312. doi:10.1002/pds.1496

[25] Osby, U., Correia, N., Brandt, L. et al. (2000) Mortality and causes of death in schizophrenia in Stockholm County, Sweden. Schizophrenia Research, 45, 21-28. doi:10.1016/S0920-9964(99)00191-7

[26] Saha, S., Chant, D., McGrath, J. (2007) A systematic review of mortality in schizophrenia: is the differential mortality gap worsening? Archives of General Psychiatry, 64, 1123-1131. doi:10.1001/archpsyc.64.10.1123

[27] The World Health Organization (WHO) (2009) Global health risks: Mortality and burden of disease attributable to selected major risks. WHO Press, Geneva. http://www.who.int/healthinfo/global-burden-disease/Glo balHealthRisks/report/full.pdf

[28] McEvoy, J.P., Meyer, J.M., Goff, D.C., et al. (2005) Prevalence of the metabolic syndrome in patients with schizophrenia: baseline results from the Clinical Antipsychotic Trials of Intervention Effectiveness (CATIE) schizophrenia trial and comparison with national estimates from NHANES III. Schizophrenia Research, 80, 19-32. doi:10.1016/j.schres.2005.07.014

[29] Newcomer, J.W. (2007) Metabolic syndrome and mental illness. American Journal of Managed Care, 13, S170S177.

[30] American Diabetes Association (ADA), American Psychiatric Association, American Association of Clinical Endocrinologists and The North American Association for the Study of Obesity (2004) Consensus development on antipsychotic drugs and obesity and diabetes. Diabetes Care, 27, 51-59.

[31] Lieberman, J.A., Stroup, T.S., McEvoy, J.P., et al. (for the Clinical Antipsychotic Trials of Intervention Effectiveness (CATIE) investigators) (2005) Effectiveness of antipsychotic drugs in patients with chronic schizophrenia. The New England Journal of Medicine, 353, 12091223. doi:10.1056/NEJMoa051688

[32] Newcomer, J.W. (2005) Second-generation (atypical) antipsychotics and metabolic side-effects: A comprehensive literature review. CNS Drugs, 19, 1-93.

[33] Rummel-Kluge, C., Komossa, K., Schwarz, S., et al. (2010) Head-to-head comparisons of metabolic side effects of second generation antipsychotics in the treatment of schizophrenia: a systematic review and meta-analysis. Schizophrenia Research, 123, 225-233.

[34] Papageorgiou, G. (2011) Country differences in patient characteristics and treatment in schizophrenia: Data from a physician-based survey in Europe. European Psychiatry, 26, 17-28. doi:10.1016/S0924-9338(11)71710-2

[35] Leitao-Azevedo, C.L., de Abreu, M.G.B., Guimaraes, L.R., et al. (2006) Overweight and obesity in schizophrenic patients taking clozapine compared to the use of other antipsychotics. Revista de Psiquiatria do Rio Grande do Sul, 28, 120-128.

[36] Hsiao, C.-C., Ree, S.-C., Chang, Y.-L., et al. (2004) Obesity in schizophrenic outpatients receiving antipsychotics in Taiwan. Psychiatry and Clinical Neurosciences, 58, 403-409. doi:10.1111/j.1440-1819.2004.01275.x

[37] Hung, C.-F. (2005) Diabetes mellitus in patients with schizophrenia in Taiwan. Progress in Neuro-Psychopharmacology and Biological Psychiatry, 28, 523-527. doi:10.1016/j.pnpbp.2005.01.003

[38] Campbell, T.C. and Chen, J.S. (1994) Chronic degenerative diseases: Perspectives from China. The American Journal of Clinical Nutrition, 56, S1153-S1173.

[39] Hirota, T., Mara, M., Ohguri, M., et al. (1992) Effect of diet and lifestyle on bone mass in Asian young women. The American Journal of Clinical Nutrition, 55, 11681173.

[40] Chien, I.-C., Hsu, J.H., Lin, C.H., et al. (2009) Prevalence of diabetes in patients with schizophrenia in Taiwan: 
A population-based National Health Insurance study. Schizophrenia Research, 111, 17-22.

[41] Ferreira, L. (2010) A case-control study of cardiovascular risk factors and cardiovascular risk among patients with schizophrenia in a country in the low cardiovascular risk regions of Europe. Revista Portuguesa de Cardiologia, 29, 1481-1493.

[42] De Leon, J. and Diaz, F.J. (2005) A meta-analysis of worldwide studies demonstrates an association between schizophrenia and tobacco smoking behaviors. Schizophrenia Research, 76, 135-157. doi:10.1016/j.schres.2005.02.010

[43] McClave, A.K., McKnight-Eily, L.R., Davis, S.P. and Dube, S.R. (2010) Smoking characteristics of adults with selected lifetime mental illnesses: results from the 2007 national health interview survey. American Journal of Public Health, 100, 2464-2472. doi:10.2105/AJPH.2009.188136

[44] Ciara, K. and McCreadis, R. (2000) Cigarette smoking and schizophrenia. Advances in Psychiatric Treatment, 6, 327-331.

[45] Kuman, V. and Postma, P. (2005) Nicotine use in schizophrenia: The self-medication hypothesis. Neuroscience \& Biobehavioral Reviews, 29, 1021-1034. doi:10.1016/j.neubiorev.2005.02.006

[46] Lavin, M.R., Sinis, S.G. and Mason, S.E. (1996) What is the clinical importance of cigarette smoking in schizophrenia? American Journal on Addictions, 5, 189-208.

[47] Mobascher, A. and Winterer, G. (2008) The molecular and cellular neurobiology of nicotine abuse in schizophrenia. Pharmacopsychiatry, 41, S51-S59. doi:10.1055/s-2008-1081463

[48] Scottish Schizophrenia Research Group (2000) Smoking habits and plasma lipid peroxide and vitamin E levels in never-treated first-episode patients with schizophrenia: Preliminary report. The British Journal of Psychiatry, 176, 290-293.

[49] Baker, A., Richmond, R. and Haile, M. (2006) A randomized controlled trial of a smoking cessation intervention among people with a psychiatric disorder. American Journal of Psychiatry, 163, 1934-1942. doi:10.1176/appi.ajp.163.11.1934

[50] Chaves, L. and Shirakawa, I. (2008) Nicotine use in patients with schizophrenia evaluated by the Fagerström Tolerance Questionnaire: A descriptive analysis from a Brazilian sample. Revista Brasileira de Psiquiatria, 30, 350-352. doi:10.1590/S1516-44462008005000014

[51] De Leon, J., Dadvard, M., Canuso, C. et al. (1995) Schizophrenia and smoking: an epidemiological survey in a state hospital. American Journal of Psychiatry, 152, 453-455.

[52] Liao, D.-L., Yang, J.-Y., Lee, S.-M., et al. (2002) Smoking in Chronic Schizophrenic Inpatients in Taiwan. Neuropsychobiology, $\mathbf{4 5}, 172-175$. doi: $10.1159 / 000063666$

[53] Herran, A., de Santiago, A., Sandoya, M., et al. (2004) Determinants of smoking behavior in outpatients with schizophrenia. Schizophrenia Bulletin, 41, 373-381.

[54] Hughes, J.R., Hatsukami, D.K., Mitchell, J.E., et al. (1986) Prevalence of smoking among psychiatric outpatients. American Journal of Psychiatry, 143, 993-997.

[55] Gu, D., Kelly, T.N., Wu, X. et al. (2009) Mortality attributable to smoking in China. The New England Journal of Medicine, 360, 150-159. doi:10.1056/NEJMsa0802902

[56] Nakanishi, N, Takatorigi, T. and Suzuki, K. (2005) Cigarette smoking and the risk of metabolic syndrome in middle-aged Japanese male office workers. Industrial Health, 43, 295-301. doi:10.2486/indhealth.43.295

[57] Oh, S.W., Yoon, Y.S., Lee, E.S. et al. (2005) Association between cigarette smoking and metabolic syndrome. Diabetes Care, 28, 2064-2066. doi:10.2337/diacare.28.8.2064

[58] Kelly, D.L., McMahon, R.P., Wehring, H.J. et al. (2011) Cigarette smoking and mortality risk in people with schizophrenia. Schizophrenia Bulletin, 37, 832-838. doi:10.1093/schbul/sbp152

[59] Dalack, G.W., Healy, D.J. and Meador-Woodruff, J.H. (1998) Nicotine dependence in schizophrenia: Clinical phenomena and laboratory findings. American Journal of Psychiatry, 155, 1490-1501.

[60] Mortensen, P.B. and Juel, K. (1993) Mortality and causes of death in first-admitted schizophrenic patients. The British Journal of Psychiatry, 163, 183-189.

[61] Folsom, D. (2009) Improving physical health care for subjects with serious mental illness. In: Meyer, J.M. and Nasrallah, H.A., Eds., Medical Illness and Schizophrenia, 2nd Edition, American Psychiatric Publishing, Washington DC, London, 3-15.

[62] Kuehn, B.M. (2010) Questionable antipsychotic prescribing remains common, despite serious risks. The Journal of the American Medical Association, 303, 15821584. doi:10.1001/jama.2010.453

[63] Morrato, E.H., Druss, B., Hartung, D.M. et al. (2010) Metabolic testing rates in 3 state medicaid programs after FDA warnings and $\mathrm{ADA} / \mathrm{APA}$ recommendations for second-generation antipsychotic drugs. Archives of General Psychiatry, 67, 17-24. doi:10.1001/archgenpsychiatry.2009.179

[64] Brenner, S. and Cohen, C.I. (2009) Medical health in aging persons with schizophrenia. In: Meyer, J.M., Nasrallah, H.A. (Eds.), Medical Illness and Schizophrenia, 2nd Edition American Psychiatric Publishing, Washington D.C. and London, pp. 377-413 at 391.

[65] Brown, S., Inskip, H. and Barraclough, B. (2000) Causes of the excess mortality of schizophrenia. British Journal of Psychiatry, 177, 212-217. doi:10.1192/bjp.177.3.212

[66] Bae, S.-W. and Brekke, J.S. (2002) Characteristics of Korean-Americans with schizophrenia: A cross-ethnic comparison with African-Americans, Latinos, and EuroAmericans. Schizophrenia Bulletin, 28, 703-717. doi:10.1093/oxfordjournals.schbul.a006974

[67] Goater, N., King, M., Cole, E., et al. (1999) Ethnicity and Outcomes of psychosis. British Journal of Psychiatry, 175, 34-42. doi:10.1192/bjp.175.1.34 